\title{
A PARTICIPAÇÃO ADULTO MADURO EM CURSOS TÉCNICOS SUBSEQUENTES
}

\author{
MATURE ADULT PARTICIPATION IN SUBSEQUENT \\ TECHNICAL COURSES
}

\author{
Nirvan Hofstadler Peixoto ${ }^{1}$ \\ Leila Maria Araújo Santos ${ }^{2}$ \\ Claudia Smaniotto Barin ${ }^{3}$
}

\begin{abstract}
RESUMO
Este estudo busca verificar a participação de adultos maduros nos cursos subsequentes em eletrotécnica, eletromecânica e mecânica do Colégio Técnico Industrial de Santa Maria, bem como averiguar de que maneira a participação desses impacta no ensino dos cursos. O presente estudo justifica-se por contribuir com a escola na identificação da faixa etária do público que procura a EPT, assim como perceber em que medida sua participação altera as formas de ensino. Por fim, visa propor alternativas para trabalhar com a diversidade geracional. Foram considerados adultos maduros, aqueles com idade igual ou superior a 35 anos, que é baseada nos estágios psicossociais de desenvolvimento do ser humanos propostos por Erikson (1972). A pesquisa foi realizada com informações da Secretaria de Registros Escolares do CTISM. Os resultados apontaram para a necessidade de um olhar mais atento aos alunos maduros, tendo em vista os seguintes aspectos: a crescente procura desses pelos cursos técnicos e as diferentes experiências e expectativas dos alunos maduros em comparação com os alunos jovens.
\end{abstract}

Palavras-chave: Adulto Maduro. Aprendizagem. Educação. Educação Profissional e Tecnológica.

\section{ABSTRACT}

This study seeks to verify the participation of mature adults in subsequent courses in electrotechnics, electromechanics and mechanics at the Colégio Técnico Industrial de Santa Maria, as well as to investigate how their participation impacts the teaching of courses. The present study is justified for contributing to the school in the identification of the age group of the public that seeks EPT, as well as perceiving to what extent their participation changes the forms of teaching. Finally, it aims to propose alternatives to work with generational diversity. Mature adults were considered to be those aged 35 or over, which is based on the psychosocial stages of human development proposed by Erikson (1972). The research was carried out with information from the CTISM School Records Secretariat. The results pointed to the need for a closer look at mature students, in view of the following aspects: the growing demand for technical courses and the different experiences and expectations of mature students compared to young students.

Keywords: Mature Adult. Learning. Education. Professional and Technological Education.

\footnotetext{
${ }^{1}$ Mestrando do Curso de Mestrado Acadêmico em Educação Profissional e Tecnológica da Universidade Federal de Santa Maria - UFSM. E-mail: nirvan.peixoto@gmail.com. Orcid: http://orcid.org/0000-0001-8169-5980. Lattes: http://lattes.cnpq.br/0031988452638678.

2 Doutora em Informática na Educação. Professora do Programa Especial de Graduação para EPT (PEG) e no Mestrado Acadêmico em Educação Profissional e Tecnológica da Universidade Federal de Santa Maria - UFSM. E-mail: leilamas@ctism.ufsm.br Orcid: https://orcid.org/0000-0002-1513-3717.Lattes: http://lattes.cnpq.br/0427736982554233. ${ }^{3}$ Doutora em Química. Professora do Programa de Mestrado Acadêmico em Educação Profissional e Tecnológica da Universidade Federal de Santa Maria - UFSM. E-mail: claudiabarin@ufsm.br ORCID: https://orcid.org/0000-0002-6549-5476_Endereço CV: http://lattes.cnpq.br/0832298305352059
} 


\section{INTRODUÇÃO}

Ao se falar em educação profissional, no Brasil, faz-se necessário uma abordagem do seu contexto histórico, pois essa carrega consigo, desde sua implantação, o estigma de ser uma educação voltada aos menos favorecidos. Segundo o documento elaborado pelo Ministério da Educação, em comemoração aos 100 anos da Rede de Educação Profissional e Tecnológica, os índios e os escravos foram os primeiros aprendizes de ofício. Com a apropriação privada da terra, os homens passaram a se dividir em duas classes: a dos proprietários de terra e a dos não proprietários, gerando uma divisão na educação. Assim, a educação que antes se identificava com o processo de trabalho, passou a ser dual: uma educação para homens livres, centrada em atividades intelectuais, e uma para os trabalhadores e escravos, voltada diretamente ao processo de trabalho, surgindo, desse modo, uma separação entre educação e trabalho (ROMANELLI, 2005; SAVIANI, 2007).

Ciavatta (2002), por sua vez, destaca que, em meados de 1930, durante o governo Vargas, a expansão capitalista e a industrialização retomaram a visão para a parte social, através da legislação sindical e trabalhista, do amparo ao trabalhador e também através da criação de escolas agrárias e técnico-industriais. Conforme Ciavatta, a constituição de 1937 assegurava, no artigo 129, que o primeiro dever do estado era a educação profissional. $\mathrm{Na}$ década de 40, surge o Sistema S que foi estruturado para oferecer uma rede de ensino que melhorasse a produtividade da mão-de-obra e serviços culturais e de lazer com financiamento garantido, mas sem depender da gestão pública.

O Decreto $n^{\circ}$ 4.127, de 25 de fevereiro de 1942 transforma as Escolas de Aprendizes e Artífices em Escolas Industriais e Técnicas, passando a oferecer a formação profissional em nível equivalente ao do secundário. O governo de Juscelino Kubitschek (1956-1961) trouxe à marca do aprofundamento a relação entre Estado e economia. No ano de 1959, as Escolas Industriais e Técnicas foram transformadas em autarquias com o nome de Escolas Técnicas Federais. As instituições ganharam autonomia didática e de gestão. Com isso, intensificou a formação de técnicos, mão de obra indispensável diante da aceleração do processo de industrialização. (WITTACZIK,2008; CIAVATTA, 2002).

A Lei de Diretrizes e Bases da Educação Brasileira - LDB, nº. 5.692, de 11 de agosto de 1971, tornou, de maneira compulsória, técnico-profissional, todo currículo do segundo grau. Um novo paradigma se estabeleceu: formar técnicos sob o regime da urgência. Nesse tempo, as Escolas Técnicas Federais aumentaram expressivamente o número de matrículas e implantaram novos cursos técnicos. 
Em 1994, a Lei no 8.948, de 8 de dezembro, dispunha sobre a instituição do Sistema Nacional de Educação Tecnológica, transformando, gradativamente, as Escolas Técnicas Federais e as Escolas Agrotécnicas Federais em Centros Federais de Educação Tecnológica CEFETs.

Em 20 de novembro de 1996, foi sancionada a Lei $\mathrm{n}^{\circ}$ 9.394, considerada como a segunda LDB, que trata sobre a Educação Profissional num capítulo separado da Educação Básica, superando enfoques de assistencialismo e de preconceito social contido nas primeiras legislações de educação profissional do país, fazendo uma intervenção social crítica e qualificada para tornar-se um mecanismo para favorecer a inclusão social e a democratização dos bens sociais de uma sociedade.

Em 2006, com o Decreto $n^{\circ}$ 5.840, foi instituído, em âmbito federal, o Programa Nacional de Integração da Educação Profissional com a Educação de Jovens e Adultos PROEJA com o ensino fundamental, médio e educação indígena. Essas mudanças buscaram alterar a visão que se tinha da educação profissional no Brasil que desde sua implantação era vista "como destinada somente a elementos das mais baixas categorias sociais" (FONSECA, 1961, p. 68).

Em 2007, houve o lançamento da segunda fase do Plano de Expansão da Rede Federal de Educação Profissional e Tecnológica, tendo como meta entregar à população mais 150 novas unidades, perfazendo um total de 354 unidades até o final de 2010.

Neste estudo, serão considerados adultos maduros aqueles com idade igual ou superior a 35 anos, de acordo com os estágios psicossociais de desenvolvimento do ser humanos propostos por Erikson (1972). Erick Erikson demandou uma teoria sobre o desenvolvimento humano em oito estágios psicossociais. Os primeiros quatros estágios são decorrentes do período de bebê ao decorrer da infância e os últimos estágios são referentes à idade adulta e à velhice.

Assim, este trabalho se justifica por identificar qual é a participação de alunos maduros nos cursos técnicos subsequentes do Colégio Técnico Industrial de Santa Maria (CTISM) e que impacto essa mudança provoca no ensino. Para tanto, uma pesquisa quantitativa foi realizada da idade dos alunos dos cursos técnicos subsequentes em Eletrotécnica, Eletromecânica e Mecânica de 2011 a 2019. Os dados foram fornecidos pelo Departamento de Ensino do CTISM, através da Secretaria de Registros Acadêmicos.

\section{A MOTIVAÇÃO DO ESTUDO}

O interesse sobre este tema "adulto maduro" provém de inquietações e motivações pessoais a partir das observações vivenciadas durante os 23 anos de atuação do autor como 
professor dos cursos técnicos subsequentes do CTISM, quando se constatou a presença cada vez maior de adultos maduros em sala de aula. Esta mescla de jovens e adultos requer um estudo mais aprofundado para atender os anseios de ambas faixas etárias que convivem em um mesmo ambiente escolar. Com o surgimento de novas tecnologias, o cotidiano das pessoas sofreu uma grande reviravolta e o ser humano vem se tornando mais dependente das Tecnologias de Informação e Comunicação (TIC) (OSÓRIO, 2003). As TIC's provocaram mudanças em todas as áreas que existem e abrem possibilidades de se desenhar uma nova visão da aprendizagem, principalmente aos adultos maduros que precisam superar as mudanças, pois cada vez mais os candidatos ao ingresso nos cursos técnicos buscam sua inserção no mercado de trabalho que é cada vez mais competitivo e exigente.

Ao apresentar os resultados deste projeto, busca-se auxiliar o CTISM na verificação da participação de adultos maduros nos cursos subsequentes e de que forma as suas participações impactam no ensino e na aprendizagem. A constante atualização do Projeto Político Pedagógico (PPP) e da estrutura curricular dos cursos técnicos, demonstram a preocupação com as mudanças no perfil dos alunos que buscam essa modalidade de ensino.

Em 2017, pela Secretaria de Educação Profissional e Tecnológica do Ministério da Educação (SETEC/MEC) e pelo Ministério da Educação (MEC) foi criada a Plataforma Nilo Peçanha (PNP) que se destina à coleta, ao tratamento e à publicação de dados oficiais da Rede Federal de Educação Profissional, Científica e Tecnológica. Nela são fornecidos uma infinidade de dados sobre a educação profissional dos anos bases de 2017 (PNP2018) e de 2018 (PNP 2019). Desse modo, como forma de auxiliar a presente pesquisa, o número de matrículas foi pesquisado por faixa etária nestes períodos. Ressalta-se que a pesquisa foi realizada levando-se em conta a modalidade de ensino presencial, em curso técnico subsequente e no eixo tecnológico: Controle e Processos Industriais, onde se enquadram os cursos técnicos subsequentes em Eletrotécnica, Eletromecânica e Mecânica que serão objetos de estudo neste projeto.

Constatou-se que, no Brasil (PNP 2018 e PNP 2019), em média, 18\% das matrículas foram de alunos com mais de 35 anos (aproximadamente 10.550 alunos). No estado do Rio Grande do Sul o percentual em média foi de $17 \%$ e no município de Santa Maria, representado pelo CTISM, apresentou média de $15 \%$ de suas matrículas com alunos com mais de 35 anos. A pesquisa na PNP também mostrou que, no ano de 2017, 13\% das matrículas eram de alunos com mais de 35 anos, percentual esse que passou para 17\% em 2018.

\section{EXPECTATIVA DE VIDA E O MERCADO DE TRABALHO}


O crescente aumento da população idosa no Brasil conduz-nos a uma nova visão para os adultos maduros e também nos instiga a pensar de que forma podemos melhorar esta parte de suas vidas. A sociedade atual tem a ideia que algumas atividades devem ser desfrutadas somente por pessoas mais jovens, porém não significa que o idoso não possa continuar aprendendo, trabalhando e tendo vida social ativa. Para Papalia e Olds (2000, p. 511), "as pessoas mais velhas podem e efetivamente continuam a adquirir novas informações e habilidades e são capazes de lembrar e usar aquelas que já conhecem".

A expectativa de vida é um reflexo das condições de vida e saúde de um determinado lugar. No Brasil a expectativa de vida está crescendo a cada ano e mostra o envelhecimento na população brasileira neste período. Isso pode ser observado pela menor porcentagem encontrada em 2018 nos grupos etários mais jovens (base da pirâmide), ao mesmo tempo em que houve aumento nas porcentagens dos grupos de idade que ficam no topo da pirâmide, segundo a pirâmide entre 2012 e 2018 apresentada na Figura1:

Figura 1 - Pirâmide Etária do Brasil entre 2012 e 2018

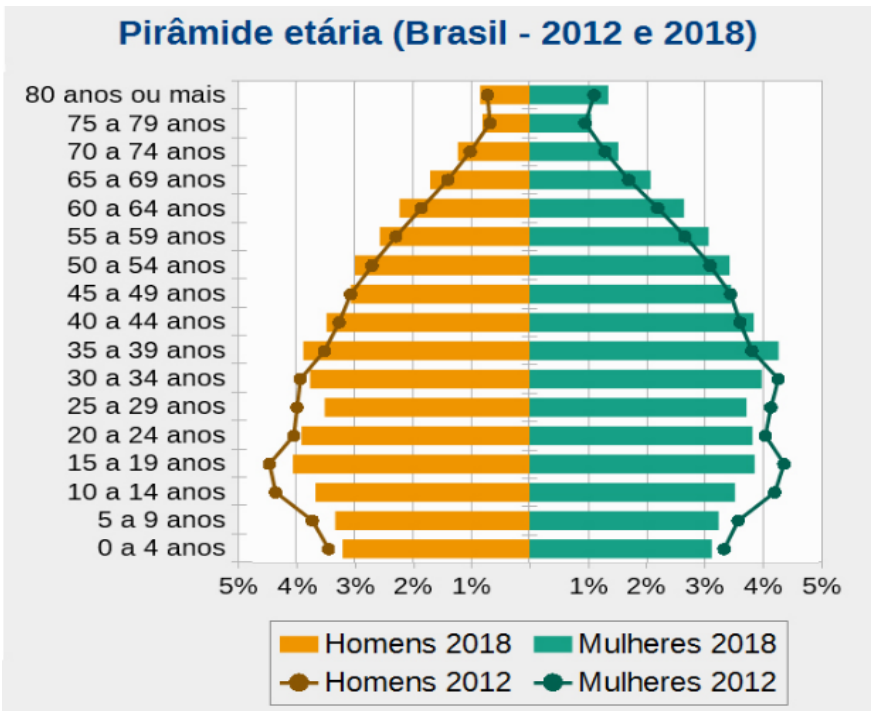

Fonte: IBGE - Pesquisa Nacional por Amostra de Domicílios Continua (PNAD) 2019

A inversão na pirâmide etária brasileira também altera o perfil daqueles que buscam a educação profissional no país. Observa-se que cada vez mais pessoas com mais idade buscam sua qualificação profissional para melhorias na renda e qualidade de vida, bem como a promoção no trabalho e a realização pessoal.

O trabalho não é visto somente como um modo de sustento, mas simboliza ainda sua realização pessoal, pois através do trabalho há um reconhecimento social (ZANELLI, SILVA, \& SOARES, 2010). Em outras palavras, existe uma necessidade nas pessoas de se sentirem úteis, capazes e produtivas como também de repassar o seu conhecimento e 
experiência profissional para os demais, estando acima do retorno financeiro que o trabalho traz (PEREIRA, 2002).

O Brasil sempre contou com a maior quantidade de brasileiros que entrava no mercado de trabalho em relação à que deixava. Hoje, o envelhecimento dos brasileiros impõe restrições ao crescimento da economia, ao mesmo tempo em que observa o declínio da Previdência Social. As despesas do Brasil com a Previdência não são compatíveis com a conjuntura econômica atual do país. De acordo com o Instituto Brasileiro de Geografia e Estatística (IBGE), o Brasil gasta mais de 13\% do seu Produto Interno Bruto (PIB) com a Previdência, percentuais muito mais altos do que países como Alemanha, Bélgica, Noruega e Suécia, países mais ricos e com maior número de idosos. Esses dados são importantes, pois sugerem a criação de políticas públicas para a inserção e permanência dos idosos no mercado de trabalho.

O IBGE 2019 mostrou que o Brasil, em meados de agosto de 2019, tinha uma população total de aproximadamente 210,15 milhões e, a partir de 2039, haverá mais idosos que crianças no país, ou seja, um a cada quatro brasileiros terá mais de 65 anos. Outra previsão é de que, em 2040, a maior parte das equipes de trabalho será de pessoas com mais de 45 anos.

Desse modo, necessita-se, com a máxima urgência, que o Estado, os empresários, a sociedade, os jovens e os idosos se unam para que possamos buscar a igualdade nas condições e oportunidades no mercado de trabalho, tanto para os mais jovens como para os idosos se tornarem mais facilmente cidadãos economicamente ativos. Ocorrendo isso, a situação da Previdência tenderá, a médio e longo prazo, a um equilíbrio (BERNARDES, L. S; CASAGRANDE, J. L.; BAINHA. 2017).

\section{A EDUCAÇÃO PROFISSIONAL NO BRASIL}

Educação Profissional no Brasil possui inúmeras designações ou formas de referência. Normalmente, refere-se como técnico profissional, educação industrial, formação profissional ou ainda qualificação. A Educação Profissional, de uma maneira geral, pode ser definida como aquela que busca construir uma base educacional que prepara o indivíduo para enfrentar o mundo globalizado e cada vez mais exigente.

A Constituição Federal em seu Art. 227 afirmou, no tocante à educação, que é dever da família, da sociedade e do estado assegurar à criança, ao adolescente e ao jovem o direito à educação e à profissionalização (BRASIL, 1988). Em consonância, a Secretaria de Educação Profissional e Tecnológica (SETEC/MEC), afirmou que a educação profissional e tecnológica (EPT) é uma modalidade educacional prevista na Lei de Diretrizes e Bases da Educação 
Nacional( LDB) com a finalidade precípua de preparar "para o exercício de profissões", contribuindo para que o cidadão possa se inserir e atuar no mundo do trabalho e na vida em sociedade.

O ensino profissional foi alvo de importantes ações, para atender suas finalidades legais, das quais, conforme Cunha (2000b, p. 196), “[...] a maioria frutificou em instituições duradouras. Mudaram os quantitativos, os destinatários, os métodos de ensino e os produtos do ensino profissional no Brasil”. A sequência histórica a seguir demonstra a evolução ou trajetória da Educação Profissional no Brasil República (BRASIL/MEC, 2008):

1909 - O presidente Nilo Peçanha assina o Decreto $n^{\circ} 7.566$ em 23 de setembro, criando as já mencionadas 19 "Escolas de Aprendizes e Artífices";

1927 - O Decreto $n^{\circ}$ 5.241, de 27 de agosto de 1927, definiu que "o ensino profissional é obrigatório nas escolas primárias subvencionadas ou mantidas pela União";

1937 - A Constituição Federal promulgada pelo Governo Getúlio Vargas tratou da educação profissional e industrial em seu Art. 129. Enfatizou o dever de Estado e definiu que as indústrias e os sindicatos econômicos deveriam criar escolas de aprendizes na esfera da sua especialidade.

1942 - O Decreto-Lei $n^{\circ}$ 4.073, de 30 de janeiro de 1942, conhecido como Lei Orgânica do Ensino Industrial, definiu que o ensino industrial será ministrado em dois ciclos: o primeiro ciclo abrange o ensino industrial básico, o ensino de mestria, o ensino artesanal e a aprendizagem; o segundo ciclo compreende o ensino técnico e o ensino pedagógico;

1942 - O Decreto-Lei $n^{\circ}$ 4.127/42, que estabeleceu as bases de organização da rede federal de estabelecimentos de ensino industrial, constituída de escolas técnicas, industriais, artesanais e de aprendizagem, extinguiu os liceus industriais, transformou em escolas industriais e técnicas, as quais passaram a oferecer formação profissional nos dois ciclos do ensino industrial;

1942 - Foi criado o SENAI (Serviço Nacional de Aprendizagem Industrial) pelo Decreto-Lei $\mathrm{n}^{\circ} 4.048$, de 22 de janeiro de 1942;

1946 - O Decreto-Lei no 9.613/46, conhecido como Lei Orgânica do Ensino Agrícola, tratou dos estabelecimentos de ensino agrícola federais;

1946 - Foi criado o Serviço Nacional de Aprendizagem Comercial - SENAC, pelo DecretoLei $\mathrm{n}^{\circ}$ 8.621, de 10 de janeiro de 1946, bem como a aprendizagem dos comerciários foi regulamentada pelo Decreto-Lei $n^{\circ}$ 8.621, do mesmo dia 10 de janeiro de 1946;

1946 - A Constituição de 1946 definiu que "as empresas industriais e comerciais são obrigadas a ministrar, em cooperação, aprendizagem aos seus trabalhadores menores, pela forma que a lei estabelecer, respeitados os direitos dos professores"; 
1959 - Foram instituídas as escolas técnicas federais como autarquias, a partir das escolas industriais e técnicas mantidas pelo Governo Federal;

1961- Em 20 de dezembro foi promulgada a Lei $n^{\circ} 4.024 / 61$. Essa foi a primeira Lei de Diretrizes e Bases da Educação Nacional (LDB) que passou a permitir que concluintes de cursos de educação profissional, organizados nos termos das Leis Orgânicas do Ensino Profissional, pudessem continuar estudos no ensino superior;

1967 - As fazendas-modelo foram transferidas do Ministério da Agricultura para o MEC e foram denominadas escolas agrícolas;

1968 - A Lei Federal $n^{\circ} 5.540$, de 28 de novembro de 1968, permite oferta de cursos superiores destinados à formação de Tecnólogos;

1971- A Lei $n^{\circ} 5.692 / 71$ definiu que todo o ensino de segundo grau, hoje denominado ensino médio, deveria conduzir o educando a conclusão de uma habilitação profissional técnica ou, ao menos, de auxiliar técnico (habilitação parcial);

1975 - A Lei Federal $n^{\circ}$ 6.297, de 11 de dezembro de 1975, definiu incentivos fiscais no imposto de renda de pessoas jurídicas (IRPJ) para treinamento profissional pelas empresas;

1978 - As Escolas Técnicas Federais do Paraná, do Rio de Janeiro e de Minas Gerais foram transformadas em Centros Federais de Educação Tecnológica (Cefets), pela Lei $\mathrm{n}^{\circ}$ 6.545, de 30 de junho;

1982 - A Lei $n^{\circ} 7.044 / 82$ reformulou a Lei $n^{\circ} 5.692 / 71$ e retirou a obrigatoriedade da habilitação profissional no ensino de segundo grau;

1991 - O Serviço Nacional de Aprendizagem Rural (SENAR) foi criado pela Lei $\mathrm{n}^{\circ} 8.315$, de 23 de dezembro de 1991, em formato institucional similar ao do SENAI e do SENAC;

1994 - Foi instituído o Sistema Nacional de Educação Tecnológica, integrado pela Rede Federal e pelas redes ou escolas congêneres dos Estados, dos Municípios e do Distrito Federal;

1996 - Em 20 de dezembro de 1996, foi promulgada a segunda Lei de Diretrizes e Bases da Educação Nacional (LDB), que dedicou o Capítulo III do seu Título VI à educação profissional.

1998-2002 - Foram definidas Diretrizes Curriculares Nacionais para a Educação Profissional de Nível Técnico, pela Resolução CNE/CEB nº 04/99, com fundamento no Parecer CNE/CEB $n^{\circ}$ 16/99; em 2002, foram definidas as Diretrizes Curriculares Nacionais Gerais para a Educação Profissional de Nível Tecnológico pela Resolução CNE/CP nº 03/2002, com fundamento no Parecer CNE/CP n ${ }^{\circ}$ 29/2002; 
2004-2008 - A Resolução CNE/CEB no 1/2004, de 21 de janeiro de 2004, definiu diretrizes nacionais para estágios supervisionados de estudantes de educação profissional e de ensino médio;

- A Resolução CNE/CEB no 1/2005, de 3 de fevereiro de 2005, atualizou as Diretrizes Curriculares Nacionais definidas para o ensino médio e Educação Profissional de nível médio; - A Resolução CNE/CEB n ${ }^{\circ}$ 3/2008, de 9 de julho de 2008, disciplinou a instituição e a implantação do Catálogo Nacional de Cursos Técnicos de Nível Médio;

2008 - Lei 11.741 introduziu importantes alterações no Capítulo III do Título V da LDB, o qual passou a tratar "da Educação Profissional e Tecnológica";

2012 - Foram definidas as atuais Diretrizes Curriculares Nacionais para a Educação Profissional Técnica de Nível Médio, pela Resolução CNE/CEB nº 6/2012;

2014 - Em 25 de junho de 2014 foi sancionada a Lei $n^{\circ}$ 13.005/2014, que aprovou o novo Plano Nacional de Educação no qual prevê "oferecer, no mínimo, 25\% (vinte e cinco por cento) das matrículas de educação de jovens e adultos, e prevê "triplicar as matrículas da educação profissional técnica de nível médio, assegurando a qualidade da oferta e pelo menos 50\% (cinquenta por cento) da expansão no segmento público";

2017- Lei ${ }^{\circ}$ 13.415/2007, que introduziu alterações na LDB (Lei ${ }^{\circ}$ 9394/1996), incluindo o itinerário formativo "Formação Técnica e Profissional" no ensino médio. A nova redação da LDB refere-se aos critérios a serem adotados pelos sistemas de ensino em relação à oferta da ênfase técnica e profissional, a qual deverá considerar "a inclusão de vivências práticas de trabalho no setor produtivo ou em ambientes de simulação, estabelecendo parcerias e fazendo uso, quando aplicável, de instrumentos estabelecidos pela legislação sobre aprendizagem profissional".

Observa-se que, muitas ações, projetos e políticas para a melhoria e inserção da educação profissional no sistema educacional brasileiro foram colocados em prática, porém com resultados tímidos e de alcance imediato ou em curto prazo. Percebe-se, também, que nos projetos implantados pelo poder público, existem diversas metas e resultado a serem atingidos, mas que na prática esbarram, principalmente, na falta de recursos financeiros, na escassez de recursos humanos capacitados, nas diversidades regionais de cunho cultural e profissional entre outros. Outro ponto importante a ser ressaltado é a falta de uma política educacional de Estado, pois o Brasil tem como característica histórica ter sempre uma política de governo, ou seja, a política voltada à educação muda toda vez que se alterna no poder outro partido político ou até mesmo outro governante.

O Plano Nacional de Educação (PNE) 2014-2024 foi instituído pela Lei nº 13.005, de 25 de junho de 2014 e estabelece diretrizes, metas e estratégias para a política educacional 
brasileira dos próximos dez anos, a partir da definição de 20 metas (PNE, 2014). Das metas estabelecidas, duas delas que estão ligadas ao ensino profissional serão comentadas. A primeira, a meta 10 é de ofertar, no mínimo, $25 \%$ (vinte e cinco por cento) das matrículas da EJA na forma integrada à educação profissional e a segunda, meta 11, de triplicar as matrículas da educação profissional técnica de nível médio, assegurando pelo menos 50\% (cinquenta por cento) da expansão no segmento público. Ao se analisar a Meta 11 do PNE não se pode deixar de refletir, que, historicamente, no Brasil, existiu a separação do ensino em duas redes, uma de educação geral para um pequeno grupo privilegiado e outra profissional para os trabalhadores. Esta leva em conta a superação da dualidade onde poucos pensam e planejam e muitos executam (trabalham). Nessa reflexão, é visível a necessidade de profissionalização da força de trabalho via uma sólida educação básica e formação técnicoprofissional de qualidade (FRIGOTTO, 1998).

De acordo com dados do Censo da Educação Básica (INEP, 2019), é possível a montagem da Figura 2 que demonstra o comportamento das matrículas nos cursos técnicos subsequentes, integrados e concomitantes.

Segundo a Relação Anual de Informações Sociais (RAIS, 2015)- "Apesar da média salarial de muitas profissões técnicas superar as de níveis superior no país, com acréscimo na renda de $18 \%$, em média, em relação a pessoas que concluíram apenas o ensino médio regular no Brasil a carreira técnica ainda sofre com preconceitos".

Figura 2 - Número de Matrículas na Educação Profissional - BRASIL - 2015 a 2019

\begin{tabular}{|c|c|c|c|c|}
\hline 1789244 & 1744630 & 1758780 & 1835791 & 1840243 \\
\hline 1023332 & 881738 & 874371 & 894863 & 962825 \\
\hline 485685 & 531843 & 554319 & 584564 & 623178 \\
\hline 278212 & 329033 & 328073 & 354346 & 252221 \\
\hline 2015 & 2016 & 2017 & 2018 & 2019 \\
\hline
\end{tabular}

Fonte: Censo Escolar 2019 - Instituto Nacional de Estudos e Pesquisas Educacionais Anísio Teixeira (INEP)

O Censo da Educação Básica 2019 ainda revela que a rede pública representa aproximadamente $53 \%$ (cinquenta e três por cento) das matrículas, indicando uma tendência de se manter e alcançar a oferta de pelo menos $50 \%$ das matrículas na rede pública. O conjunto de medidas/políticas apresentadas atende, em parte, a demanda existente por EPT, tornando viável e favorável a transição do sistema educacional ao mundo do trabalho. 
Após inúmeras pesquisas e leituras sobre EPT e educação de adultos e adultos maduros, chega-se à conclusão que no Brasil muito pouco é realizado para atender a faixa etária dos 35 aos 65 anos de idade, pois a maioria das políticas está voltada somente para a EJA. A inserção deste público na educação formal é de suma importância. Apesar do aumento expressivo dos índices educacionais obtidos pelo Brasil, existem muitos questionamentos sobre sua qualidade e a efetiva inclusão desse público na vida produtiva.

\section{METODOLOGIA}

Esta pesquisa foi pensada a partir da literatura com referenciais teóricos que versam sobre dualidade e jovens adultos, buscando conexões importantes sobre a Educação Profissional e Tecnológica e o Colégio Técnico Industrial. Trata-se de uma pesquisa com forte enfoque qualitativo, mas que também se apropria de dados quantitativos para realizar suas análises. Sendo assim, a pesquisa foi desenvolvida em duas etapas com foco a atingir os objetivos propostos. Na primeira etapa, foram realizadas leituras e interpretação de livros, periódicos e de artigos acadêmicos disponibilizados na internet que ilustraram o desenvolvimento das políticas públicas em EPT. Em uma segunda etapa, buscou-se, junto à Secretaria Escolar do CTISM, por meio de uma pesquisa documental, traçar o perfil dos discentes dos cursos subsequentes em eletrotécnica, eletromecânica e mecânica.

Os cursos de eletrotécnica e mecânica formam técnicos desde o início das atividades do CTISM em 1967 e o curso de eletromecânica desde o ano de 1994. A mostra da população alvo desta pesquisa constituiu-se dos alunos do CTISM, regularmente matriculados no segundo ano nos referidos cursos, no período compreendido entre 2011 e 2019.

\section{COLETA DE DADOS REALIZADA JUNTO À SECRETARIA ESCOLAR DO CTISM}

Com base nas informações prospectadas, foram realizados estudos para determinar a idade média dos alunos dos três cursos objeto deste estudo. Os dados estatísticos recebidos da secretaria escolar do CTISM, com a data de nascimento de cada aluno por ano de ingresso. Esses dados foram tabulados, classificados e trabalhados para permitir uma visão do comportamento da idade dos alunos no decorrer dos últimos anos. Para o cálculo das idades de cada aluno, foi considerada a idade dos discentes em primeiro de março (01/março) de cada ano estudado, ou seja, a idade em primeiro de março de 2011 e assim por diante até o ano de 2019.

Nesse cálculo, foi utilizada uma planilha de cálculo do Excel e optou-se por uma casa decimal com arredondamento matemático. Não foram atribuídos critérios de inclusão ou 
exclusão de participantes, portanto, foram considerados todos os alunos que constam dos dados enviados pela secretaria escolar do CTISM

Para este estudo, foram considerados "adultos maduros" sujeitos com idade igual ou superior a 35 anos, indivíduos em fase de transição do adulto jovem para o adulto idoso. A opção do uso desta nomenclatura/termo "adulto maduro" está baseada nos estágios psicossociais de desenvolvimento do ser humano propostos por Erik Erikson (1972). A tabela 1 que segue, demonstra os estágios no desenvolvimento psicossociais de Erikson, objetos deste estudo.

Tabela 1 - Desenvolvimento Psicossocial segundo Erikson

\begin{tabular}{|c|c|c|c|}
\hline \multicolumn{4}{|c|}{ DESENVOLVIMENTO PSICOSSOCIAL SEGUNDO ERIKSON } \\
\hline \multirow{2}{*}{ Estágio } & \multirow{2}{*}{$\begin{array}{l}\text { Idade } \\
\text { Aprox. }\end{array}$} & \multicolumn{2}{|c|}{ Resolução da crise } \\
\hline & & Êxito & Fracasso \\
\hline $\begin{array}{l}\mathbf{5}^{2} \text { Idade: } \\
\text { Adolescente }\end{array}$ & $\begin{array}{c}12 \text { a } 20 \\
\text { anos }\end{array}$ & $\begin{array}{l}\text { Saber quem é e o que quer da vida. Segurança, independência. } \\
\text { É capaz de aprender muito. Vinculos sociais estáveis e abertos }\end{array}$ & $\begin{array}{l}\text { Não sabe o que quer. Não sabe situar-se face } \\
\text { ao trabalho, à sociedade e à sexualidade. }\end{array}$ \\
\hline $\begin{array}{c}\sigma^{2} \text { Idade: } \\
\text { Jovem Adulto }\end{array}$ & $\begin{array}{c}20 \text { a } 35 \\
\text { anos }\end{array}$ & $\begin{array}{l}\text { Capacidade de amar e de se entregar Sexualidade } \\
\text { enriquecedora Vinculos sociais estáveis e abertos }\end{array}$ & $\begin{array}{l}\text { Dificuldade em relacionar-se Relações } \\
\text { inautênticas, efêmeras, problemáticas, instaveis. }\end{array}$ \\
\hline $\begin{array}{l}7^{2} \text { Idade: } \\
\text { Adulto }\end{array}$ & $\begin{array}{c}35 \text { a } 65 \\
\text { anos }\end{array}$ & $\begin{array}{l}\text { Produtivo e criativo. Projetado para o futuro. Gosta de } \\
\text { colaborar com as novas gerações }\end{array}$ & $\begin{array}{c}\text { Improdutivo, acabado. Preocupado consigo } \\
\text { próprio, egocêntrico }\end{array}$ \\
\hline
\end{tabular}

Fonte: ERIKSON, E. H. Identidade, Juventude e Crise - 1972. Adaptado pelo autor

O objetivo geral desta etapa da pesquisa é de identificar a faixa etária (segundo os estágios de Erikson) dos alunos que buscam o CTISM e, caso exista, constatar se há alguma tendência. De posse de todos os dados fornecidos pela secretaria escolar do CTISM, foi realizada uma análise por curso/ano de ingresso, dos estágio de Erikson dos alunos recém matriculados. Os cursos escolhidos são todos na modalidade presencial, cursos técnicos subsequentes ao ensino médio e classificados no eixo tecnológico de controle e processos industriais, segundo a Plataforma Nilo Peçanha (PNP). Ao se efetuar uma pesquisa na Plataforma Nilo Peçanha (PNP), obtiveram-se os dados relativo aos anos bases de 2017 (PNP 2018) e de 2018 (PNP 2019), apresentados na Tabela 1, que demonstram o comportamento das idades dos alunos para a modalidade de ensino presencial, curso técnico subsequente e no eixo tecnológico de controle e processos industriais (igual aos cursos estudados neste trabalho).

\section{ACHADOS DA PESQUISA}

\section{Análise dos dados coletados junto à secretaria de registro escolares do CTISM}




\section{Participação de adultos Maduros}

Os dados, depois de recebidos, foram tabulados e organizados de forma a facilitar as análises necessárias, separados por curso e por ano de acesso. É importante ressaltar que não houve critérios de inclusão ou exclusão de participantes, sendo, portanto, considerados todos os alunos enviados pela secretaria escolar do CTISM.

Efetuando-se uma análise da Tabela 2, pode-se verificar que houve um acréscimo de $1 \%$ no número de matrículas na faixa de idade de 35 anos até mais de 60 anos, tanto no Brasil como na região Sul e que no estado do Rio Grande do Sul e no município de Santa Maria o acréscimo foi muito significativo, isto é, quatro vezes maior. Verifica-se também que o número de matrículas de alunos com mais de 35 anos no RS e em SM representa quase que um quinto (1/5) do total de matrículas nestes cursos.

Tabela 2 - Matrículas por Faixa Etária

\begin{tabular}{|c|c|c|c|c|c|c|c|c|c|c|c|c|c|c|c|c|}
\hline \multirow{4}{*}{\begin{tabular}{|c} 
Faixa \\
Etária
\end{tabular}} & \multicolumn{16}{|c|}{ MATRÍCULAS POR FAIXA ETÁRIA } \\
\hline & \multicolumn{4}{|c|}{ BRASIL } & \multicolumn{4}{|c|}{ REGIÃO SUL } & \multicolumn{4}{|c|}{ RIO GRANDE DO SUL } & \multicolumn{4}{|c|}{ SANTA MARIA } \\
\hline & \multicolumn{2}{|c|}{2018} & \multicolumn{2}{|c|}{2019} & \multicolumn{2}{|c|}{2018} & \multicolumn{2}{|c|}{2019} & \multicolumn{2}{|c|}{2018} & \multicolumn{2}{|c|}{2019} & \multicolumn{2}{|c|}{2018} & \multicolumn{2}{|c|}{2019} \\
\hline & 25.062 & $83 \%$ & 23.207 & $82 \%$ & 6.610 & $80 \%$ & 6167 & $79 \%$ & 3454 & $85 \%$ & 2637 & $81 \%$ & 616 & $87 \%$ & 427 & $83 \%$ \\
\hline $\begin{array}{c}35 \\
\mathrm{a} \\
60\end{array}$ & 5.244 & $17 \%$ & 5.266 & $18 \%$ & 1.652 & $20 \%$ & 1676 & $21 \%$ & 607 & $15 \%$ & 631 & $19 \%$ & 95 & $13 \%$ & 88 & $17 \%$ \\
\hline
\end{tabular}

Fonte: Plataforma Nilo Peçanha (PNAD 2018 e PNAD 2019) - Adaptado pelo autor

A escolha destes cursos deve-se ao fato de eles atenderem a indústria metalmecânica, estarem plenamente alinhados com a EPT, serem cursos com mais de 10 anos de existência, formarem profissionais para a área técnica industrial e serem cursos de atuação docente do autor por mais de 22 anos, bem como a visualização efetiva, no dia-a-dia em sala de aula, do aparecimento de um contingente maior de alunos maduros. Uma das primeiras preocupações na análise dos dados foi a de atender o objetivo geral deste trabalho, que é "verificar a participação de adultos (35 ou mais anos de idade) nos cursos técnicos subsequentes de eletrotécnica, eletromecânica e mecânica do CTISM".

A Figura 3, a seguir, apresenta a contribuição em percentual do Estágio Adulto, nos cursos de eletrotécnica, eletromecânica e mecânica. Observa-se que, nos anos de 2011 a 2013, não houve nenhuma matrícula desde estágio nos cursos. Outro ponto que chama a atenção é o curso de mecânica que só foi ter matrícula de adulto no ano de 2017, isso quer dizer que durante seis anos (2011 a 2016) não ocorreu o ingresso adultos no curso. Independentemente do fato de não existir matrículas nos primeiros anos deste estudo, contatou-se visualmente, por meio da Figura 4, que há uma tendência de aumento deste estágio nos cursos. Outro ponto a salientar é do curso de eletrotécnica que apresenta o maior percentual de contribuição do 
estágio na maioria dos anos do estudo e que no ano de 2019 apresentou uma participação de quase $23 \%$ de adultos no total de matrículas. Em contraposição, o curso de mecânica é o que apresentou uma das menores contribuições inclusive com nenhuma matrícula nos seis primeiros anos da pesquisa (2011 a 2016):

Figura 3 - Contribuição Percentual do Estágio Adulto Maduro

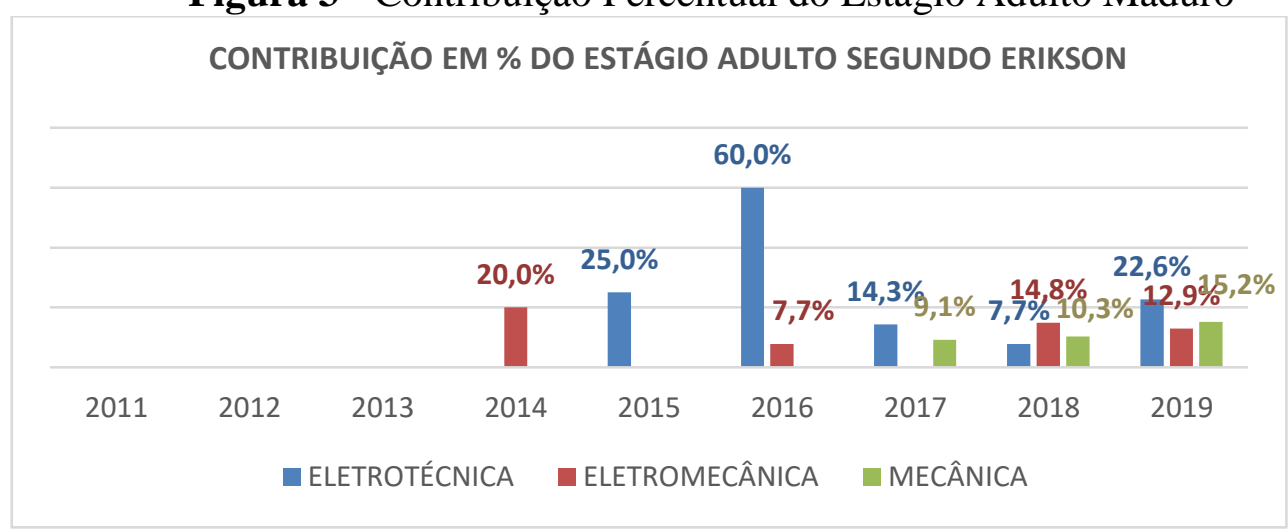

Fonte: Dados da Secretaria de Registros Escolares do CTISM - Adaptado pelo autor.

Desses mesmos dados, é possível obter-se a contribuição média em percentual dos três cursos, para o estágio adulto nos nove anos estudados, representado pela Figura 4. Por seu intermédio, é possível visualizar que, no curso de mecânica, o estágio adulto representa, em média, somente três vírgula oito por cento $(3,8 \%)$ do total de matrículas, sendo o menor percentual dentre os três cursos. Por outro lado, o curso de eletrotécnica apresenta a maior contribuição com quatorze vírgula quatro por cento $(14,4 \%)$ do número de matriculas do curso.

Figura 4 - Média de Idade dos alunos nos 3 Cursos.

\begin{tabular}{|c|c|c|}
\hline \multicolumn{3}{|c|}{$\begin{array}{c}\text { CONTRIBUIÇÃO MÉDIA NO NÚMERO DE } \\
\text { MATRÍCULAS DO ESTAGIO ADULTO POR CURSO } \\
14,4 \%\end{array}$} \\
\hline $3,8 \%$ & $6,2 \%$ & 工 \\
\hline MECÂNICA & ELETROMECÂNICA & ELETROTÉCNICA \\
\hline
\end{tabular}

Fonte: Dados da Secretaria de Registros Escolares do CTISM - Adaptado pelo autor.

Após a análise dos dados referentes a adultos, pode-se, com certeza, concluir que a participação de adultos está aumentando como também possui uma tendência de continuar crescendo. Esse público em 2019 representou um sexto (1/6) do total de matrículas nestes três cursos. Um fato que pode dificultar uma tomada de decisões pela escola é pela heterogeneidade na participação de adultos nos cursos. Como exemplo prático, pode-se citar o curso de eletrotécnica que apresentou na maioria dos anos a maior participação de adultos maduros e em contraposição o curso de mecânica a menor. 


\subsubsection{Determinação da Faixa Etária}

Para a determinação da faixa etária dos alunos que buscam os cursos subsequentes de eletrotécnica, eletromecânica e mecânica do CTISM foi elaborada a Tabela 3 com os dados fornecidos. Ao analisar a Tabela 3, uma das primeiras constatações é de que o curso de Eletrotécnica apresenta a média mais alta de idade dentre os ingressantes destes cursos. A média é aproximadamente quatro anos a mais do que a dos alunos do curso de mecânica e de 2,6 anos a mais do que a eletromecânica. Outro ponto importante constatado quando da análise da Tabela é que existe um crescimento da idade média dos ingressantes dos três cursos. Ao se comparar a média de idade do início do período estudado, 2011, com o final do período (2019) constatou-se que no curso de eletrotécnica houve um acréscimo de 5,8 anos, na eletromecânica de 7,3 anos e no curso de mecânica de 7,8 anos. Se utilizar-se este mesmo estudo levando-se em conta os estágios de Erikson, pode-se afirmar que, em 2011, a média de idade dos cursos de eletromecânica e mecânica é adolescente e o curso de eletrotécnica de jovens adultos. Em 2019, a média de idade dos três cursos é de jovens adultos.

Tabela 3 - Média de Idade dos Alunos nos Três Cursos.

\begin{tabular}{|c|c|c|c|c|c|c|c|c|c|c|}
\cline { 2 - 13 } \multicolumn{1}{c|}{} & \multicolumn{7}{c|}{ MÉDLA DE DADE DOS ALUNOS } & MÉDIA \\
\cline { 2 - 12 } & 2011 & 2012 & 2013 & 2014 & 2015 & 2016 & 2017 & 2018 & 2019 & CURSO \\
\hline ELETROTÉCNICA & 24,5 & 22,0 & 20,3 & 22,2 & 29,4 & 35,0 & 25,7 & 25,7 & 30,3 & 26,1 \\
\hline ELETROMICÂNICA & 19,3 & 23,0 & 23,3 & 24,2 & 24,7 & 19,9 & 22,1 & 28,1 & 26,6 & 23,5 \\
\hline MECÂNICA & 19,0 & 23,5 & 21,7 & 21,2 & 21,6 & 20,4 & 22,2 & 23,5 & 26,8 & 22,2 \\
\hline MÉDLA DOS CURSOS & 20,9 & 22,8 & 21,8 & 22,5 & 25,2 & 25,1 & 23,3 & 25,8 & 27,9 & 24 \\
\hline
\end{tabular}

Fonte: Dados da Secretaria de Registros Escolares do CTISM

Outra visualização que se pode praticar é que a média de idade, no conjunto dos três cursos aumentou ao longo do período. A Figura 5 mostra o crescimento da média de idade de ingresso nos três cursos ao longo dos anos, como também foi inserida uma linha de tendência que aponta para um crescimento da idade média nos cursos. A linha de tendência linear é uma linha reta que mostra, dentro da série de dados, se os mesmos tendem a aumentar ou diminuir ao longo do tempo.

Figura 5 - Contribuição Média do estágio Adulto Maduro no número de matrículas

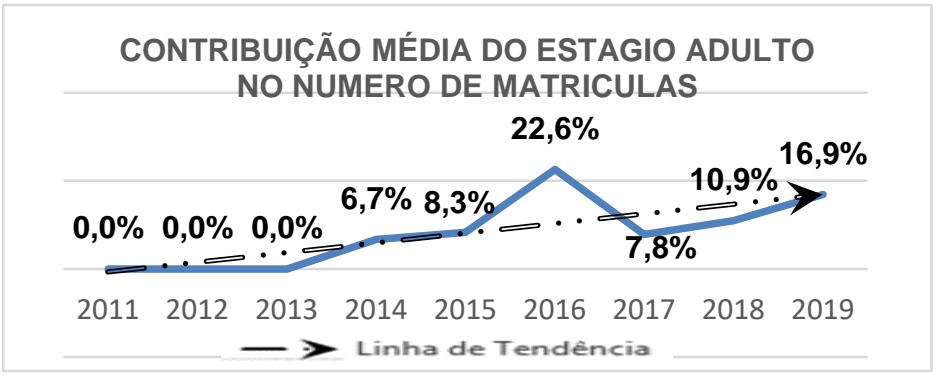


Fonte: Dados da Secretaria de Registros Escolares do CTISM - Adaptado pelo autor

A tabela 4 apresenta a contribuição de todos os estágios de Erikson durante o período estudado e, de uma forma geral, demonstrou que a maior participação de alunos dos três cursos pertence ao estágio jovem adulto, que se situa na faixa de 20 a 35 anos de idade. $\mathrm{Na}$ maioria dos anos analisados, o estágio apresentou a maior contribuição no número de matrículas em todos os cursos e nunca inferior a cinquenta por cento $(50 \%)$. Ocorreram de forma aleatória algumas mudanças pontuais na contribuição do estágio em determinados cursos.

Tabela 4 - Idade Média dos alunos por curso e ano de ingresso

\begin{tabular}{|c|c|c|c|c|c|c|c|c|c|c|}
\hline \multicolumn{11}{|c|}{ CONTRIBUIÇÃO EM \% POR ESTÁGIOS SEGUNDO ERIKSON } \\
\hline CURSO & ESTÁGIO & 2011 & 2012 & 2013 & 2014 & 2015 & 2016 & 2017 & 2018 & 2019 \\
\hline \multirow{3}{*}{ 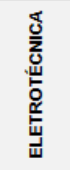 } & ADOLESCENTE & $100,00 \%$ & $100,00 \%$ & $50,00 \%$ & $33,30 \%$ & $12,50 \%$ & $20,00 \%$ & $21,40 \%$ & $19,20 \%$ & $61,30 \%$ \\
\hline & JOVEM ADULTO & $0,00 \%$ & $0,00 \%$ & $50,00 \%$ & $66,70 \%$ & $62,50 \%$ & $40,00 \%$ & $64,30 \%$ & $73,10 \%$ & $16,10 \%$ \\
\hline & ADULTO & $0,00 \%$ & $0,00 \%$ & $0,00 \%$ & $0,00 \%$ & $25,00 \%$ & $40,00 \%$ & $14,30 \%$ & $7,70 \%$ & $22,60 \%$ \\
\hline \multirow{3}{*}{ 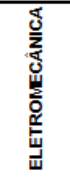 } & ADOLESCENTE & $66,70 \%$ & $20,00 \%$ & $0,00 \%$ & $20,00 \%$ & $28,60 \%$ & $38,50 \%$ & $40,00 \%$ & $7,40 \%$ & $12,90 \%$ \\
\hline & JOVEM ADULTO & $33,30 \%$ & $80,00 \%$ & $100,00 \%$ & $60,00 \%$ & $71,40 \%$ & $53,80 \%$ & $60,00 \%$ & $77,80 \%$ & $74,20 \%$ \\
\hline & ADULTO & $0,00 \%$ & $0,00 \%$ & $0,00 \%$ & $20,00 \%$ & $0,00 \%$ & $7,70 \%$ & $0,00 \%$ & $14,80 \%$ & $12,90 \%$ \\
\hline \multirow{3}{*}{ 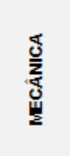 } & ADOLESCENTE & $100,00 \%$ & $0,00 \%$ & $41,70 \%$ & $16,70 \%$ & $50,00 \%$ & $46,20 \%$ & $31,80 \%$ & $24,10 \%$ & $15,20 \%$ \\
\hline & JOVEM ADULTO & $0,00 \%$ & $100,00 \%$ & $58,30 \%$ & $83,30 \%$ & $50,00 \%$ & $53,80 \%$ & $59,10 \%$ & $65,60 \%$ & $69,70 \%$ \\
\hline & ADULTO & $0,00 \%$ & $0,00 \%$ & $0,00 \%$ & $0,00 \%$ & $0,00 \%$ & $0,00 \%$ & $9,10 \%$ & $10,30 \%$ & $15,10 \%$ \\
\hline
\end{tabular}

Fonte: Dados da Secretaria de Registros Escolares do CTISM - Adaptado pelo autor

De posse da tabela 4, é possível a obtenção da Figura 8 que apresenta a contribuição de cada estágio no total de matrículas dos três cursos. Detectou-se logo a primeira mão que o estágio jovem adulto (idade entre 20 a 35 anos) é responsável por mais da metade das matrículas nestes cursos $(53,5 \%)$ e que a contribuição do estágio adolescente é de trinta e oito vírgula quatro por cento $(38,4 \%)$. O estágio adulto contribuiu, aproximadamente, com somente oito por cento do total das matrículas.

Figura 3 - Contribuição Média de cada estágio no Total de Matrículas

Contribuição média em \% de cada estágio no total de matrículas

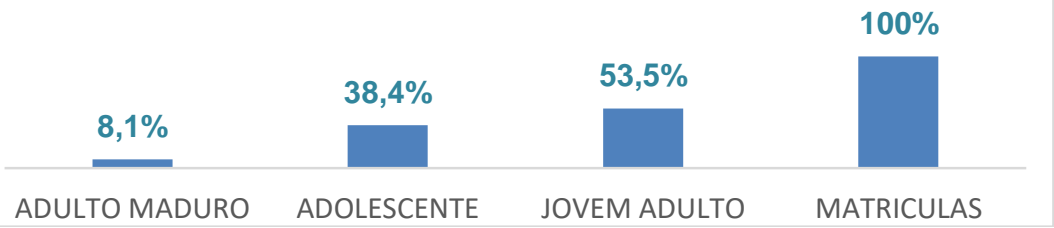

Fonte: Dados da Secretaria de Registros Escolares do CTISM - Adaptado pelo autor 
Após este estudo, foi possível afirmar que a faixa etária dos alunos que buscam os cursos subsequentes de eletrotécnica, eletromecânica e mecânica do CTISM situam-se no estágio de jovem adulto de Erikson, ou seja, na faixa de idade compreendida entre 20 e 35 anos de idade. Esses representam mais da metade das matrículas como afirmado acima, sendo a média de idade para todos os cursos de 24 anos no período dos nove (9) anos estudados.

\section{CONSIDERAÇÕES FINAIS}

Ao finalizar este trabalho, percebe-se o quanto é desafiador o processo de ensino de adultos maduros e o quanto ainda precisa ser estudado para se alinhar às necessidades e às expectativas deste público. O público jovem (20-34 anos) e o adulto maduro (35-60 anos) trazem consigo uma bagagem de experiências práticas pessoais e profissionais aliado as dificuldades inerentes ao ensino profissional noturno tais como o cansaço físico, pois a maioria trabalha durante o dia, a interferência direta do trabalho com as horas-extras, a troca de turnos de trabalho, o pouco tempo para estudar fora da sala de aula, o tempo de deslocamento trabalho/escola, além da diversidade geracional. Portanto, deve-se reavaliar o processo de ensino-aprendizagem para atender especificamente a esse público

A educação brasileira, no tocante a formação de trabalhadores, de qualquer faixa etária, recebe pouca atenção do governo, o que é facilmente percebido pela falta de estrutura e carência de estatísticas oficiais. Durante a execução deste trabalho, quando da busca por dados da EPT, ficou clara a falta de estrutura e de preparo para tratar a EPT como merece. Os dados encontrados são escassos, muitas vezes conflitantes, imprecisos e incompletos. Pesquisas em sites oficiais do Governo mostraram por diversas vezes dados desencontrados ou até contraditórios. Informações sobre EPT voltadas para jovens e adultos são muito raras e, em sua maioria, estão direcionadas à EJA ou ao PROEJA (integrado). Dados sobre o profissional de nível médio são quase inexistentes e quando acontecem são casos pontuais e voltados à determinada instituição de ensino ou microrregião.

Considerando que a Educação Profissional no Brasil teve seu início oficial com o Decreto $\mathrm{n}^{\circ} 7.566$ de 1909 possuindo mais de um século de história, deveria ter dados e informações pertinentes. Na verdade, a realidade mostra que a maioria dos dados foi perdida no decorrer do tempo. A Plataforma Nilo Peçanha (PNP) demonstrou que é possível concentrar e organizar os dados, as estatísticas da EPT, todas em um mesmo local, porém os resultados práticos devem demorar, pois só tem disponíveis dados dos anos bases 2017 e 2018.

Ao analisar os dados apresentados nesta pesquisa, dos cursos subsequentes do CTISM (eletromecânica, eletrotécnica e mecânica), verifica-se que em sua totalidade existe uma 
tendência para o aumento do público jovem e do adulto. A mudança do perfil dos alunos foi percebida, de forma empírica, tanto pelos docentes como pela direção da escola e esta preocupação está marcada pela reformulação do Projeto Político Pedagógico (PPP) da maioria de seus cursos técnicos de nível médio em 2019, com vigência a partir de 2020. Os dados demonstraram, também, o amadurecimento dos alunos que buscam a EPT no CTISM, pois do ano de 2011 ao ano de 2019, a média de idade dos alunos passou de 22,9 anos para 29 anos.

Durante a análise de todos os dados, verificou-se que a idade média dos alunos que realizaram matrículas vem aumentando a cada ano, mostrando uma tendência de se ter cada vez mais um número maior de alunos com mais de 20 anos assim como alunos com mais de 35 anos. No ano de 2019, esse público representou aproximadamente 17\% (dezessete por cento) do total de alunos e ao se reportar aos anos de 2011 a 2013, verifica-se que o percentual era de $0 \%$ (zero por cento). Considerando que a oferta de vagas é de 32 por curso, 17\% a um número de aproximadamente 5,5 alunos com 35 anos ou mais.

Os resultados quantitativos relativos ao aluno maduro do CTISM, embora pontuais, assemelharam-se a dados nacionais no que tange a EPT quanto ao aumento da procura por esta modalidade de ensino por pessoas de mais idade. $\mathrm{O}$ aluno mais velho que hoje está no CTISM necessita de maiores investigações e estudos, pois se percebe as dificuldades e interesses diversos daqueles dos colegas e talvez dos docentes. A Tecnologia da Informação e Comunicação (TIC) e as Metodologias Ativas devem ser amplamente utilizadas e difundidas no processo de aprendizagem, pois são propulsoras dos processos de ensino e da inclusão digital, independentemente de idade, classe social, raça ou religião. Tudo também associado à capacitação pedagógica dos docentes, por meio de cursos específicos, para fazer frente ao novo perfil discente. Essa capacitação é necessária e imediata para que o docente permaneça como um facilitador da aprendizagem e não reproduza os erros do passado.

Sendo assim, na visão do pesquisador, acredita-se que o estudo atingiu o seu propósito e a resposta da questão de pesquisa é de que a presença de alunos maduros em sala de aula impacta o processo de ensino, tendo em vista que os alunos maduros possuem experiências e necessidades distintas ao dos alunos jovens e isso merece uma maior atenção por parte de professores e instituição.

Portanto, o estudo mostrou que um olhar mais atento ao aluno maduro se faz necessário, já que os mesmos estão em desvantagens etárias para a inserção no mundo do trabalho e a Educação Profissional é hoje a porta de entrada ao mundo do trabalho, trazendo como resultado, progresso econômico e social do país. 


\section{REFERÊNCIAS}

BERNARDES, L. S.; CASAGRANDE, J. L.; BAINHA, A. Envelhecimento da População e a Previdência Social: as possibilidades existentes de aposentadorias no Brasil e suas regras. Ciências Sociais Aplicadas em Revista. 2017. Disponível em:< http://erevista.unioeste.br/index.php/csaemrevista/article/view/18632>. Acesso em: 15 jan. 2020.

BORGES, G. M.; CAMPOS, M. B. de; SILVA, L. G. C. e. Transição da estrutura etária no Brasil: oportunidades e desafios para a sociedade nas próximas décadas. In: ERVATTI, L. R.; BORGES, G. M.; JARDIM, A. P. Mudança Demográfica no Brasil no Início do Século XXI: Subsídios para as projeções da população. Rio de Janeiro: IBGE, 2015. n. 3. p. 138-51.

BRASIL. Instituto Nacional de Estudos e Pesquisas Educacionais Anísio Teixeira. Plano Nacional de Educação PNE-2014-2024: Linha de Base. - Brasília, DF: Inep, 2015. 404 p.: il.

. Lei $\mathbf{n}^{0}$ 8.948, de 08 de dezembro de 1994. Cria o Conselho Nacional do Idoso e dá outras providências. Diário Oficial da República Federativa do Brasil, Brasília, DF, 20 dez. 1996. Disponível em: http://www.planalto.gov.br. Acesso em: 22 maio de 2015.

.Lei $\mathrm{n}^{\circ}$ 9.394, de 20 de dezembro de 1996. Estabelece as diretrizes e bases da educação nacional. Diário Oficial [da] República Federativa do Brasil, Brasília, DF, 20 dez. 1996. Disponível em: http://www.planalto.gov.br. Acesso em: 22 maio de 2015.

CIAVATTA, M. A construção da democracia pós-ditadura militar - políticas e planos educacionais no Brasil. In: FÁVERO, O; SEMERARO, G. (Org.). Democracia e construção do público no pensamento educacional brasileiro. 2. ed. Petrópolis, Rio de Janeiro: Vozes, 2002.

CUNHA, L. A. O ensino de ofícios nos primórdios da industrialização. São Paulo: UNESP, 2000b. 243 p.

ERIKSON, E. H. Identidade, Juventude e Crise. Rio de Janeiro: Zahar, 1972.

FRIGOTTO, G. Educação, crise do trabalho assalariado e do desenvolvimento: Teorias em conflito. In: (Org.). Educação e crise do trabalho: perspectiva de final de século. Petrópolis: Vozes, 1998.

FONSECA, C. S. História do ensino industrial no Brasil. Rio de Janeiro: Escola Técnica, 1961

IBGE. INSTITUTO BRASILEIRO DE GEOGRAFIA E ESTATÍSTICA. Disponível em: < https://educa.ibge.gov.br/jovens/conheca-o-brasil/populacao/18318-piramide-etaria.html>. Acesso em: 30 jan. 20.

OSÓRIO, A. R. Educação Permanente e Educação de Adultos. Lisboa: Instituto Piaget, 2003.

PAPALAIA, D. E.; OLDS, S. W. Desenvolvimento Humano. $7^{\text {a }}$ Ed. Porto Alegre, Artes Médicas Sul, 2000. 
PEREIRA, D. E. C. Qualidade de vida na terceira idade e sua relação com trabalho no grupo de terceira idade: "Amor e Carinho" de Santa Terezinha de Itaipu. Dissertação de Mestrado. Universidade Federal de Santa Catarina, 2002.

ROMANELli, O de O. História da Educação no Brasil: 1930-1973. 8. ed. Petrópolis: Vozes, 1986.

SAVIANI, D. História das ideias pedagógicas no Brasil. São Paulo: Campinas. Ed. Autores associados, 2007.

Zanelli, J. C.; Silva, N.; Soares, D. H. P. Orientação para aposentadoria nas organizações de trabalho: Construção de projetos para o pós-carreira. Porto Alegre: Artmed, 2010.

WITTACZIK, L. S. Educação Profissional no Brasil: histórico. In.: E-Tech: Atualidades Tecnológicas para Competitividade Industrial, Florianópolis, v. 1, n. 1, p. 77-86, $1^{\circ}$. sem., 2008.

Artigo Recebido: 29 de março de 2021.

Artigo Aceito: 24 de abril de 2021. 